\title{
Genetic analysis for the grain number heterosis of a super-hybrid rice WFYT025 combination using RNA-Seq
}

\author{
Liang Chen ${ }^{1,2+}$, Jianmin Bian ${ }^{1,2,3^{* \dagger}} \mathbb{D}$, Shilai Shi ${ }^{1,2+}$, Jianfeng $Y u^{1,2}$, Hira Khanzada ${ }^{1,2}$, Ghulam Mustafa Wassan ${ }^{1,2}$, \\ Changlan Zhu $u^{1,2,3}$, Xin Luo ${ }^{1,2}$, Shan Tong ${ }^{1,2}$, Xiaorong Yang ${ }^{1,2}$, Xiaosong Peng ${ }^{1,2,3}$, Shuang Yong ${ }^{1}$, Qiuying Yu ${ }^{1}$, \\ Xiaopeng $\mathrm{He}^{1,2}$, Junru Fu ${ }^{1,2}$, Xiaorong Chen ${ }^{1,2}$, Lifang Hu${ }^{1,2,3}$, Linjuan Ouyang ${ }^{1,2}$ and Haohua He $\mathrm{e}^{1,2,3^{*}}$
}

\begin{abstract}
Background: Despite the great contributions of utilizing heterosis to crop productivity worldwide, the molecular mechanism of heterosis remains largely unexplored. Thus, the present research is focused on the grain number heterosis of a widely used late-cropping indica super hybrid rice combination in China using a high-throughput next-generation RNA-seq strategy.

Results: Here, we obtained 872 million clean reads, and at least one read could maps 27,917 transcripts out of 35,679 annotations. Transcript differential expression analysis revealed a total of 5910 differentially expressed genes (DGHP) between super-hybrid rice Wufengyou T025 (WFYT025) and its parents were identified in the young panicles. Out of the 5910 DG $\mathrm{HP}_{\mathrm{P}}, 63.1 \%$ had a genetic action mode of over-dominance, $17.3 \%$ had a completedominance action, $15.6 \%$ had a partial-dominance action and $4.0 \%$ had an additive action. DG HP $_{\text {were significantly }}$ enriched in carotenoid biosynthesis, diterpenoid biosynthesis and plant hormone signal transduction pathways, with the key genes involved in the three pathways being up-regulated in the hybrid. By comparing the DGHP enriched in the KEGG pathway with QTLs associated with grain number, several DG $\mathrm{HP}_{\mathrm{P}}$ were located on the same chromosomal segment with some of these grain number QTLS.

Conclusion: Through young panicle development transcriptome analysis, we conclude that the over-dominant effect is probably the major contributor to the grain number heterosis of WFYT025. The DGHP sharing the same location with grain number QTLs could be considered a candidate gene and provide valuable targets for the cloning and functional analysis of these grain number QTLs.
\end{abstract}

Keywords: Rice, Super-hybrid Rice, Heterosis, Grain number, RNA-seq

\section{Background}

Heterosis is a phenomenon in which hybrids exhibit superiority over their parental lines in economic traits, such as enhanced biomass production, development rate, stress tolerance and, most important, grain yield. Heterosis has been extensively used to increase crop productivity throughout the world. A major increase in rice yield was caused by the application of heterosis. Because of the key role of heterosis, the molecular mechanisms should be elucidated. In the

\footnotetext{
* Correspondence: jmbian81@126.com; hhhua64@163.com

+Liang Chen, Jianmin Bian and Shilai Shi contributed equally to this work.

${ }^{1}$ Key Laboratory of Crop Physiology, Ecology and Genetic Breeding, Ministry

of Education, Jiangxi Agricultural University, Nanchang 330045, China

Full list of author information is available at the end of the article
}

early twentieth century, dominance (Davenport 1908) and over-dominance (Shull 1908) were used to explain heterosis. However, with nothing about molecular concepts being covered, consequently, they cannot interpret the molecular genetic mechanisms of heterosis (Birchler et al. 2003). With the development of polymerase chain reaction (PCR), molecular markers have been widely used to identify the distance between the hybrid and its parents and to build the relationship between heterosis and genetic distance. However, marker PCR can only be used to classify heterotic groups and determine genetic diversity, but it cannot predict heterosis because the coefficient of the relationship between the genetic distance of SSR markers and yield 
heterosis is very small (Xu et al. 2009). Subsequently, molecular markers and hybrid genetic analysis have been used to locate QTLs for heterosis. A Pioneer study of the heterosis gene qGY2-1 related to yield was reported in haplotype populations (He et al. 2006). To eliminate the epistasis effect among QTLs, Bian et al. (2011) used chromosome segment substitution lines (CSSLs) to study heterosis for yield traits in indica $\times$ japonica hybrid rice subspecies. With the advent of high-throughput sequencing technology, scientists conducted DNA sequencing of 1495 elite hybrid rice varieties and their inbred parental lines. Comprehensive analyses of heterozygous genotypes have revealed that heterosis mainly resulted from the accumulation of numerous superior alleles with positive dominant effects (Huang et al. 2015).

In addition, the association of heterosis with differentially expressed transcripts was also investigated at the RNA level. Wei et al. (2009) investigated differentially expressed transcripts from tissues at different growth development stages using super rice LYP9 and its parents and found that the differentially expressed transcripts were closely related to QTLs in response to heterosis. Huang et al. (2006) used 9198 unique sequence tags to study gene differential expression profiles of young panicles using the super rice SY63 combination and suggested that transcripts controlling DNA repair and replication were up-regulated and that the genes related to carbohydrate, energy and lipid metabolism, translation and protein degradation were down-regulated.

High-throughput RNA sequencing has been used to search for heterosis in rice to avoid defects of methods with low throughput, high cost, low sensitivity, clonal preference, and high background noise. RNA-seq was first used to compare the transcriptome profiles of reciprocal hybrids from Nipponbare and 93-11, along with their parents, at the seedling stage. In total, 2800 genes showed differential expression, and these transcripts were involved in energy metabolism, especially in the Calvin cycle, in which six key components were up-regulated ( $\mathrm{He}$ et al. 2010). Later, Zhai et al. (2013) compared the transcriptome between super hybrid XY9308 and its parents through RNA-seq, which indicated that carbohydrate metabolism and plant hormone signal transduction were enriched in differentially expressed transcripts.

In this study, we focused on heterosis in the rice WFYT025, a widely used late-cropping indica super hybrid rice combination in China. The number of filled grains, one of the most important yield heteroses in yield contributing factors, showed great differences between WFYT025 and its female parent. Thus, we conducted transcriptome analysis using young panicles from the WFYT025 combination by high-throughput RNA-seq to detect the correlation of key transcripts with filled grain number heterosis. Some key transcripts were mapped in the QTL interval related to grain number. Revealing the function of these transcripts may provide useful information for understanding the molecular mechanism underlying heterosis.

\section{Results \\ Phenotype analysis for WFYT025 and its parents}

In this study, we investigated the yield-related traits of WFYT025 and its parents. It was found that the panicles of WFYT025 and its male parent CHT025 were larger than those of the female parent WFB, and their grain number and primary branch number were also higher than those in WFB (Fig. 1a and b). However, no significant differences were observed between WFYT025 and parental line CHT025 for both grain number and primary branch number (Fig. 1b). Mid-parent heterosis $(\mathrm{MPH})$ and higher parent heterosis $(\mathrm{HPH})$ were estimated for the heterosis of panicles. The MPH for all of the traits except the seed setting ratio and tiller remained significant (Table 1). Traits such as primary branch number, secondary branch number, filled grain number, empty grain number and 1000-grain weight were significant for the MPH at $p<0.05$, while traits such as spike length, total grain number and yield per plant were highly significant at $p<0.01$. The MPH showed negative effects on the seed setting ratio. Apart from the seed setting ratio and empty grain number, the $\mathrm{MPH}$ values for all of the traits varied from 1.16 to $32.32 \%$. In addition, $\mathrm{HPH}$ for yield per plant remained highly significant $(22.99 \%)$ at the $p<0.01$ level. Further analysis indicated that significant difference for yield per plant was mainly due to the large $\mathrm{MPH}$ range for filled grain numbers $(20.01 \%)$ and 1000-grain weight (6.25\%). This implied that compared to the 1000 -grain weight, the yield heterosis was more likely to underlay the filled grain number between hybrid WFYT025 and maternal line WFB.

\section{Identification of transcripts by sequencing}

A total of 917 million raw reads were generated using the high-throughput Illumina HiSeq 2500 platform. The paired-end sequences with low-quality reads containing adapters were trimmed off. Finally, 87.2 million clean reads were obtained (Table 2). The correlation for the gene expression level from three biological replicates of each line was $0.97<R^{2}<0.99$. (Additional file 1 : Figure S1). We pooled the short reads and aligned them to the Nipponbare reference genome (IRGSP v1.0) to identify the transcripts. Out of 35,679 identified transcripts, 27,917 transcripts were mapped, covering $78.24 \%$ of the genome. In addition, the transcriptome profile of WFYT025 was similar to that of its female parent WFB (Fig. 2). 

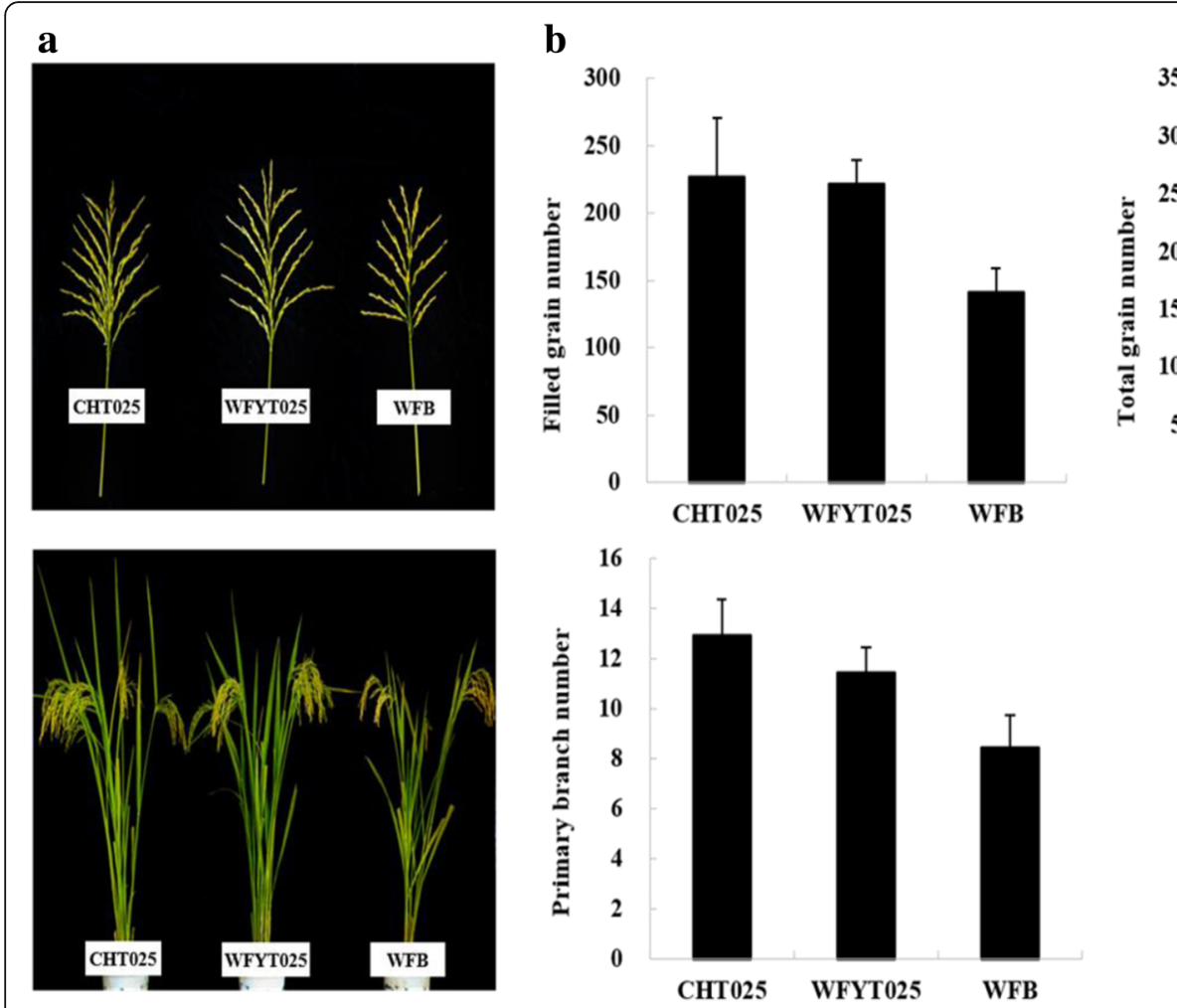

Fig. 1 Comparisons of super hybrid WFYT025 combination. a The upper panel illustrates the panicles from combination of super hybrid WFYT025. Left, CHT025; middle, WFYT025; right, WFB. The lower panel shows the combination of super hybrid WFYT025. Left, CHT025; middle, WFYT025; right, WFB. b Panicle traits of CHT025, WFYT025, and WFB

\section{Validation of gene expression by quantitative real-time PCR (qRT-PCR)}

To validate the results of mRNA sequencing data, the expression of a subset of 15 randomly selected $\mathrm{DG}_{\mathrm{HP}}$ was determined by qRT-PCR. The list of primer sequences is presented in Additional file 2: Table S1. The results obtained from qRT-PCR and RNA-seq were compared, and expression trends were consistent for all transcripts in both analyses; the correlation coefficient $\left(\mathrm{R}^{2}\right)$ was 0.9339 (Fig. 3).

\section{Analysis of differentially expressed genes (DEGs)}

We adopted reads per kilobase million reads (FPKM) to measure gene expression levels. Two criteria were considered to identify putative DEGs: (1) the false discovery rate (FDR) should be $\leq 0.05$ and (2) the fold change (FC)

Table 1 Phenotypic Analysis of Super Hybrid WFYT025 Combination

\begin{tabular}{|c|c|c|c|c|c|}
\hline Traits & CHT025 & WFYT025 & WFB & MPH (\%) & $\mathrm{HPH}(\%)$ \\
\hline Spike length $(\mathrm{cm})$ & $23.24 \pm 1.75$ & $24.34 \pm 0.67$ & $19.61 \pm 1.71$ & $13.64^{* *}$ & 4.74 \\
\hline Primary branch number & $12.89 \pm 1.45$ & $11.45 \pm 1.00$ & $8.46 \pm 1.26$ & $7.10^{*}$ & -11.21 \\
\hline Secondary branch number & $49.26 \pm 9.66$ & $45.67 \pm 5.44$ & $26.51 \pm 5.21$ & $20.39^{*}$ & -7.28 \\
\hline Solid grain number & $227.40 \pm 42.72$ & $221.43 \pm 18.30$ & $141.42 \pm 17.60$ & $20.01^{*}$ & -2.63 \\
\hline Total grain number & $251.36 \pm 40.39$ & $247.08 \pm 21.20$ & $151.21 \pm 17.89$ & $22.64^{* *}$ & -1.70 \\
\hline Empty grain number & $23.95 \pm 6.52$ & $25.65 \pm 10.68$ & $9.78 \pm 2.49$ & $51.30^{*}$ & 7.08 \\
\hline Seed setting ratio (\%) & $89.65 \pm 0.04$ & $89.04 \pm 4.29$ & $93.05 \pm 1.62$ & -2.54 & -5.16 \\
\hline 1000-grain weight (g) & $18.64 \pm 0.92$ & $22.44 \pm 0.63$ & $23.60 \pm 0.34$ & $6.25^{*}$ & -5.15 \\
\hline Tiller & $6.8 \pm 0.92$ & $8.7 \pm 1.25$ & $10.4 \pm 2.50$ & 1.16 & -16.34 \\
\hline Yield per plant (g) & $29.89 \pm 7.02$ & $42.8 \pm 2.80$ & $34.8 \pm 6.89$ & $32.32^{* *}$ & $22.99^{* *}$ \\
\hline
\end{tabular}

**Significant difference with $p<0.01$

* Significant difference with $p<0.05$ 
Table 2 Number of Mapped Reads

\begin{tabular}{llll}
\hline Sample & Total Reads & Mapped Reads & Mapping Ratio (\%) \\
\hline CS & $27,507,194$ & $22,157,870$ & 80.55 \\
YS & $21,214,278$ & $17,312,734$ & 81.61 \\
BS & $38,511,686$ & $31,076,870$ & 80.69 \\
Total & $87,233,158$ & $70,547,474$ & 80.95 \\
\hline
\end{tabular}

CS, YS and BS stand for the samples from CHT025, WFYT025, WFB, respectively

should be $\geq 2$. Following these criteria, 4160 DEGs have been identified between paternal line CHT025 and WFYT025. Of these, 2155 DEGs were up-regulated and 2005 were down-regulated. Additionally, 2809 DEGs were identified between maternal line WFB and WFYT025, of which 1463 DEGs were up-regulated and 1346 DEGs were down-regulated (Table 3). For a detailed comparison, the FPKM of all transcripts is presented in Additional file 3: Table S2. DEGs between parents are designated $\mathrm{DG}_{\mathrm{PB}}$ and DEGs among the hybrid and parents are designated $D_{G_{H P}}$. $\mathrm{DG}_{\mathrm{HP}}$ may be relevant to heterosis because differences in expression between hybrids and parents should underlie their phenotypic differences. While $\mathrm{DG}_{\mathrm{PP}}$ only refers to the differences among the two parental lines (Song et al. 2010), there are still $3223 \mathrm{DG}_{\mathrm{HP}}$ that overlapped with $\mathrm{DG}_{\mathrm{PB}}$ which indicates that these $\mathrm{DG}_{\mathrm{PP}}$ are also associated with heterosis (Fig. 4). In addition, $1059 \mathrm{DG}_{\mathrm{HP}} \mathrm{S}$ were shared between the hybrid and both of its parents.

\section{The mode of inheritance for $\mathrm{DG}_{\mathrm{HP}}$}

Using the method to evaluate the mode of inheritance, $\mathrm{DG}_{\mathrm{HP}}$ were classified into four expression patterns: over-dominance ( $\mathrm{Hp} \leq-1.2$ or $\mathrm{Hp}>1.2)$, dominance ($1.2<\mathrm{Hp} \leq-0.8$ or $0.8<\mathrm{Hp} \leq 1.2)$, additive effect $(-0.2<$ $\mathrm{Hp} \leq 0.2)$, and partial dominance $(-0.8<\mathrm{Hp} \leq-0.2$ or
$0.2<\mathrm{Hp} \leq 0.8$ ) (Additional file 4: Table S3). As shown in Fig. 5, these data suggested that the over-dominant effect, dominant effect, partially dominant effect and additive effect accounted for $63.1 \%, 17.3 \%, 15.6 \%$ and $4.0 \%$, respectively.

\section{Functional classification of $\mathrm{DG}_{\mathrm{HP}}$ by Gene Ontology (GO)} We applied Gene Ontology (GO) to classify the function of the mRNA. Using Web Gene Ontology Annotation Plot (WEGO) software (Ye et al. 2006), we distributed $5910 \mathrm{DG}_{\mathrm{HP}}$ into at least one term in the GO molecular function, cellular component, and biological process categories. Further analysis showed that $5910 \mathrm{DG}_{\mathrm{HP}}$ were present in 54 functional subcategories at a significance level of $p<0.05$ (Fig. 6). In the cellular function category, cells and cell parts were mainly divided in the groups. For the molecular function category, $\mathrm{DG}_{\mathrm{HP}}$ was enriched with binding and catalytic activity. With respect to biological processes, cellular and metabolic processes were highly enriched in $\mathrm{DG}_{\mathrm{HP}}$. We further analysed the $\mathrm{GO}$ terms of $\mathrm{DG}_{\mathrm{HP}}$ enriched with the biological process subcategories. These GO terms, including response to stimulus, cell proliferation, carbohydrate metabolic process, organ formation, and gibberellin biosynthetic process, may underlie heterosis in the young panicle of WFYT025 (Tables 4 and 5).

\section{DG $\mathrm{HP}_{\mathrm{P}}$ mapping Kyoto Encyclopedia of Genes and Genomes (KEGG) pathway}

For the identification of metabolic pathways in which $\mathrm{DG}_{\mathrm{HP}}$ were involved and enriched, the Kyoto Encyclopedia of Genes and Genomes pathway database was used. In total, 118 pathways were identified in 613 $\mathrm{DG}_{\mathrm{HP}}$ (between paternal line CHT025 and hybrid line WFYT025). The top 20 most enriched pathways mainly

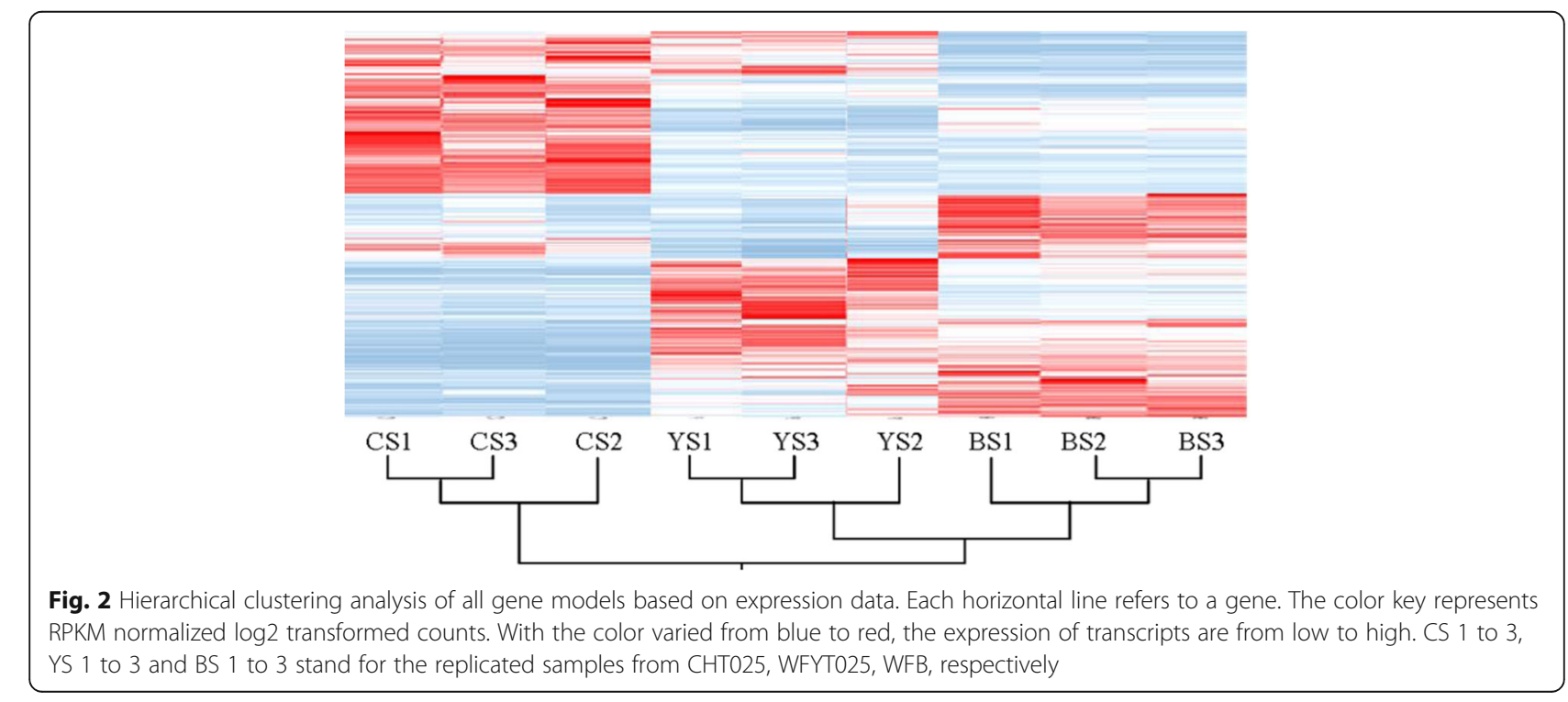




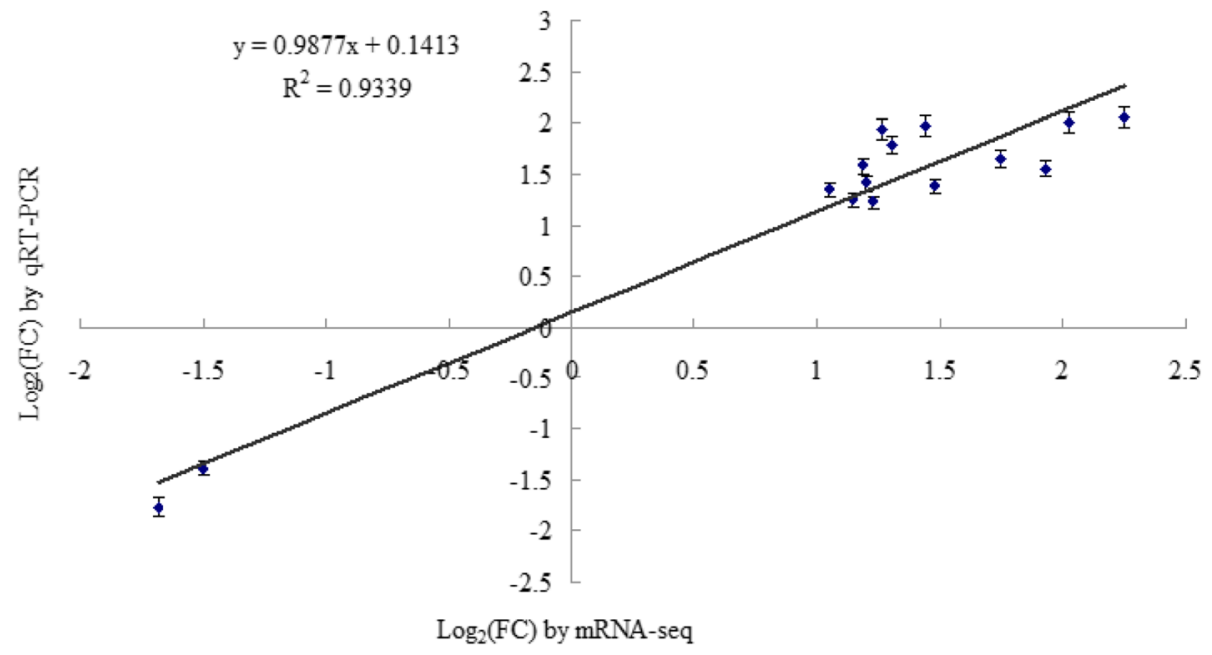

Fig. 3 Comparison of the log2 (FC) of 15 randomly selected transcripts using RNA-Seq and qRT-PCR

covered carbon fixation in photosynthetic organisms, DNA replication, fatty acid biosynthesis and metabolism, and phenylpropanoid biosynthesis (Fig. 7a). In contrast, $268 \mathrm{DG}_{\mathrm{HP}}$ between maternal line WFB and WFYT025 were classified into 107 pathways, and the top 20 most enriched pathways were mainly concentrated in plant hormone signal transduction, carotenoid biosynthesis, diterpenoid biosynthesis, zeatin biosynthesis, and cysteine and methionine metabolism with a significance level of $p<0.05$ (Fig. 7b). This suggests that the considerable differences in young panicles between WFB and WFYT025 may be related to hormone regulation.

Comparison of $\mathrm{DG}_{\mathrm{HP}}$ with grain yield-related genes (QTLs) We were able to map the $\mathrm{DG}_{\mathrm{HP}}$ that were significant in the KEGG analysis $(P<0.05)$ between WFYT025 and WFB for the QTLs associated with grain yield in the rice genome (http://www.gramene.org). As shown in Table 6, a total of 36 transcripts were mapped in the interval of 22 yield-related QTLs, including 15 grain number QTLs, 6 1000-grain weight QTLs and 1 yield per plant QTL. Most genes shared the same location with one yield-related QTL. However, Os03g0856700 corresponded to $q G P 3-1$ for grain number and $q S N P-3 b$ for spikelet number per panicle. Os04g0229100 was mapped to the same loci as qGwt4a for 1000-grain weight and $q S N P-4 a$ for spikelet number per panicle, while Os04g0578400 and Os04g0608300

Table 3 Number and Classification of $\mathrm{DG}_{\mathrm{HP}}$

\begin{tabular}{lll}
\hline Pattern & WFYT025 / CHT025 & WFYT025 / WFB \\
\hline Up & 2155 & 1463 \\
Down & 2005 & 1346 \\
Total & 4160 & 2809 \\
\hline
\end{tabular}

shared the same chromosome segment with qGPP-4 for grain number per panicle and $q S N P 4-1$ for spikelet number per panicle.

\section{Discussion}

Though heterosis has been extensively exploited in plant breeding and plays an important role in agriculture, the molecular and genetic mechanisms underlying this phenomenon remain poorly understood. Differential gene expression between a hybrid and its parents may be associated with heterosis ( $\mathrm{He}$ et al. 2010; Kim et al. 2013; Zhang et al. 2008). Here, we investigated the relationship between transcriptional profiles and heterosis in super hybrid rice WFYT025 by RNA-Seq.

\section{Comparative analysis of $\mathrm{DG}_{\mathrm{HP}}$}

Using RNA-Seq analysis, 872 million high-quality paired-end reads of 150 bp were generated from the panicles of WFYT025 and its parental lines at the panicle differentiation stage, and 27,917 annotated transcripts were identified. Of these transcripts, $4160 \mathrm{DG}_{\mathrm{HP}}$ between hybrid WFYT025 and paternal line CHT025 and $2809 \mathrm{DG}_{\mathrm{HP}}$ between hybrid WFYT025 and maternal line WFB were identified.

The filled grain number heterosis exhibited significant differences between WFYT025 and WFB; however, there were no significant differences between WFYT025 and CHT025 (Fig. 1b, Table 1). Therefore, the results suggest that the expression of $\mathrm{DG}_{\mathrm{HP}}$ between WFYT025 and WFB at the young panicle development stage may play an important role in grain number heterosis compared to that between WFYT025 and CHT025. Therefore, focusing on the expression of $\mathrm{DG}_{\mathrm{HP}}$ between WFB and WFYT025 might find an association between $\mathrm{DG}_{\mathrm{HP}}$ and heterosis for filled grain number. 


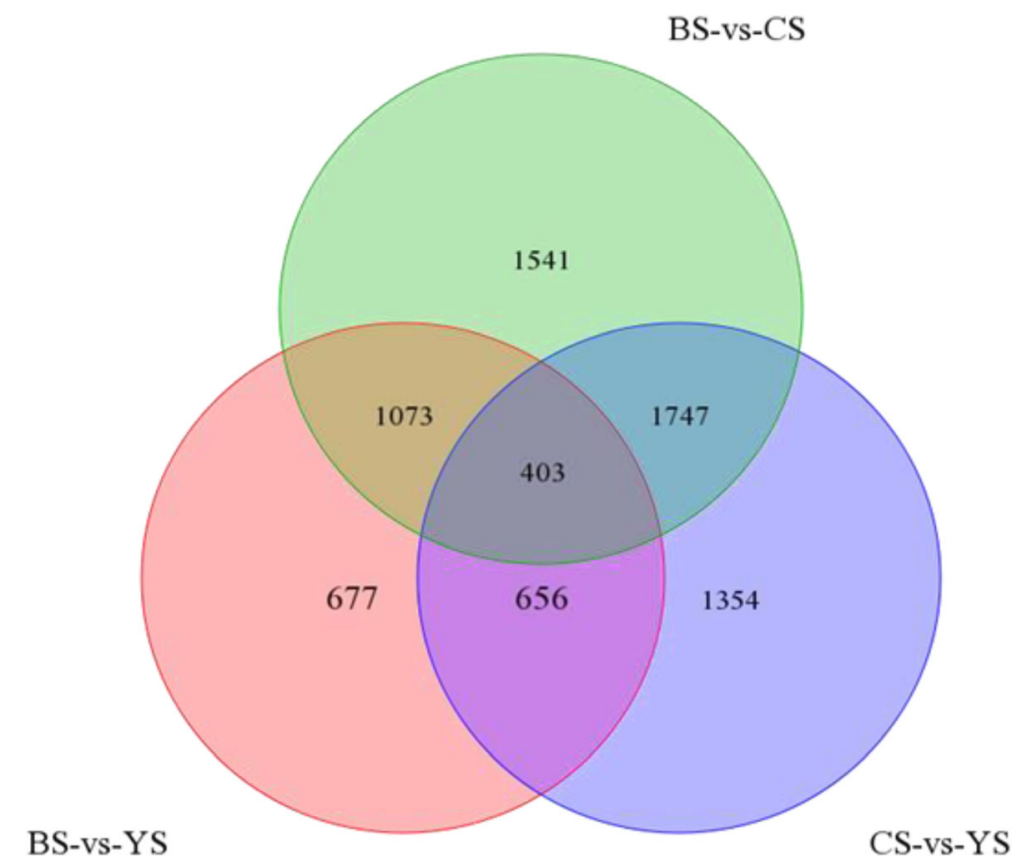

Fig. 4 DEGs in super hybrid WFYT025 combination. Venn diagram of DEGs between the hybrid and its parents. CS, YS and BS represent CHT025, WFYT025 and WFB, respectively

\section{The genetic basis of heterosis}

We have been able to identify a number of $\mathrm{DG}_{\mathrm{HP}} \mathrm{s}$ underlying grain number between hybrid WFYT025 and maternal line WFB, confirming the suggestion that heterosis is a polygenic phenomenon (Kusterer et al. 2007; Bian et al. 2011). Among the $D G_{H B} 17.3 \%$ had a dominant effect, $15.6 \%$ had a partial dominant effect, $4 \%$ had an additive effect and the remaining $63.1 \%$ had an over-dominant effect. Thus, over-dominance was the major contributor to the heterosis of WFYT025.

Meanwhile, the expression differences of cloned yield trait genes have been investigated between the hybrid and its parents. Of the 143 genes related to grain yield traits,
11 genes, accounting for $7.7 \%$, showed over-dominance; 12 genes, accounting for $8.3 \%$, showed dominance; 71 genes, accounting for $49.6 \%$, showed partial dominance; and 49 genes, accounting for $34.4 \%$, showed partial dominance (Additional file 5: Table S4).

\section{The role of hormone signal transduction in heterosis}

It is well known that hormones act as signalling molecules in plants and can regulate physiological responses. Transcriptome analysis has uncovered many $\mathrm{DG}_{\mathrm{HP}} \mathrm{S}$ that are involved in the phytohormone response in young panicle tissue. For example, mRNA levels of Os12g0586100 encoding SNF1-related protein kinase2 (SnRK2), whose

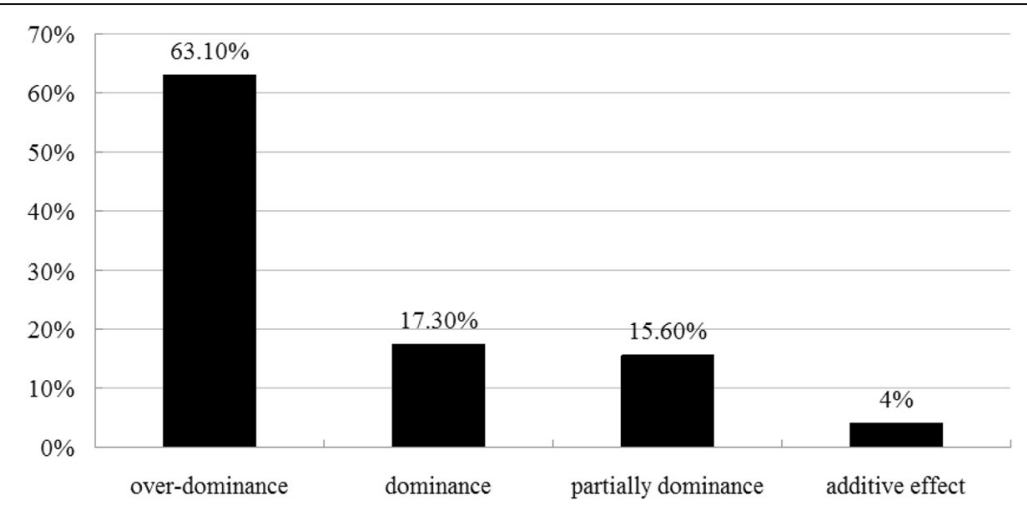

Fig. 5 Breakdown of the DGHP according to the dominance ratio Hp. Depending on the principal of $\mathrm{Hp}=[\mathrm{d}]$ / [a], Hp was classified as either positive or negative 

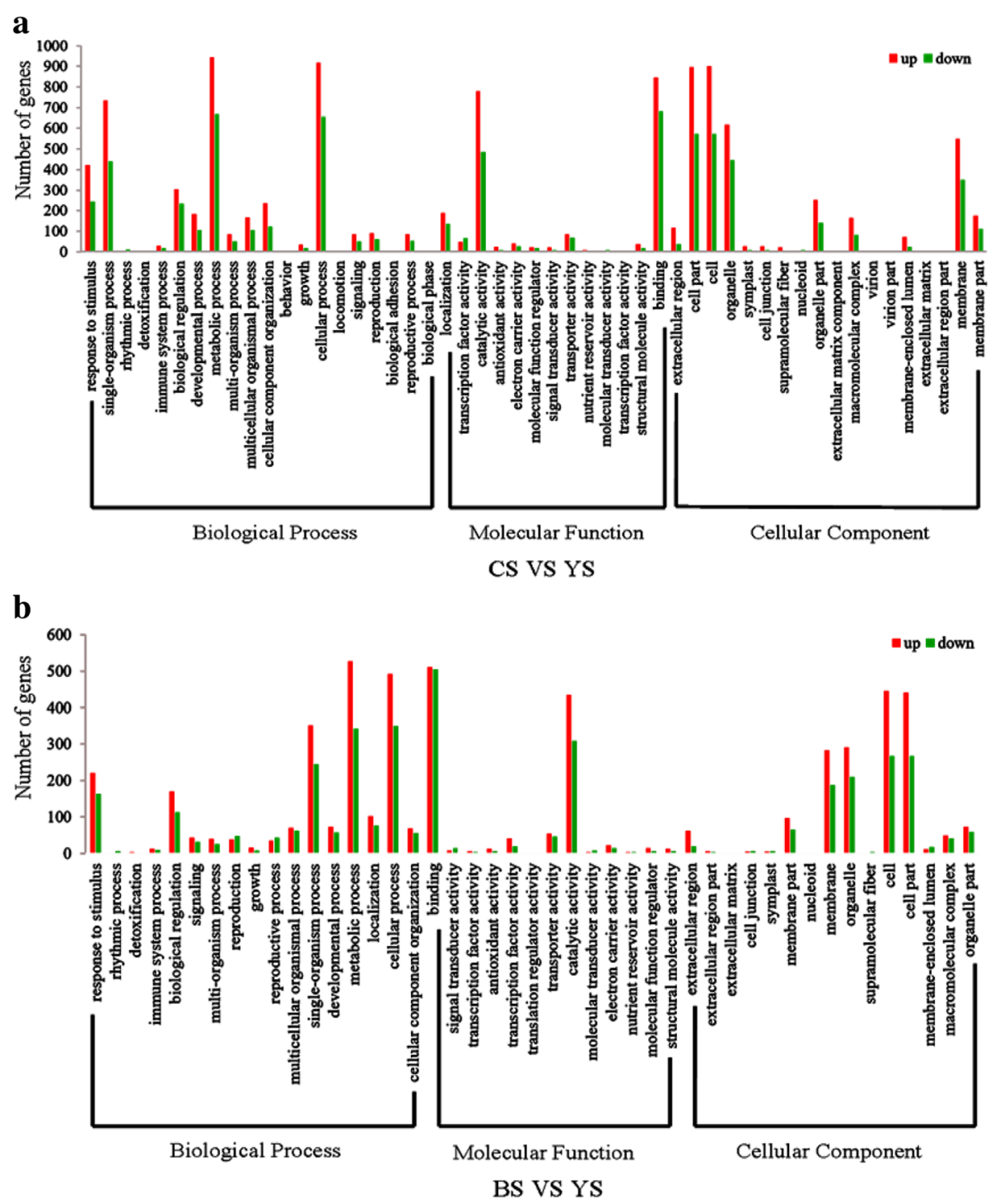

Fig. 6 Comparison of Gene Ontology (GO) classifications of DGHP. a CS and YS represent CHT025 and WFYT025 respectively. Red column and green column represent up-regulated and down-regulated transcripts respectively. b BS and YS represent WFB and WFYT025 respectively. Red column and green column represent up-regulated and down-regulated transcripts respectively

autophosphorylation is required for kinase activity towards downstream targets, were expressed poorly in WFYT025 compared to its parents. In addition, type- $2 \mathrm{C}$ protein phosphatase (PP2C, a negative regulator) (Os01g0846300, Os05g0572700, Os01g0656200 and Os03g0268600) was up-regulated, and a similar observation was also reported by Merlot et al. (2001) and Zhai et al. (2013). These results are consistent with the negative-feedback regulatory mechanism in ABA signal transduction.

Moreover, transcripts involved in the gibberellin (GA) biosynthesis pathway were also differentially expressed between the hybrid and its two parents, in this study. GAs are a large family of diterpenoid compounds, some of which are bioactive growth regulators that control flower development
(Cowling et al. 1998). GAs are involved in the transformation of vegetative reproduction to reproductive growth (Poethig 1990; Evans and Poethig 1995). OsGA200x1 (Os03g0856700) encodes a GA20 oxidase, which is the key enzyme that catalyses the penultimate step reaction of gibberellin biosynthesis and enhances the grain number of rice by increasing the cytokinin activity in the rice panicle meristem (Wu et al. 2016). In this study, we observed that the expression level of OsGA20ox1 in WFYT025 is up-regulated 2-fold higher than in WFB and showed over-dominance (Additional file 5: Table S4). This suggested that WFYT025 may possess strong potential for gibberellin biosynthesis compared to maternal line WFB, which promoted the amount of spikelet primordium in hybrid line WFYT025. 


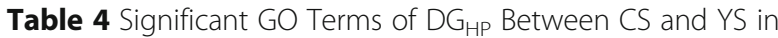
the Biological Process Category

\begin{tabular}{lll}
\hline GO ID & Description & $p$-value \\
\hline GO:0042221 & Response to chemical & 0.000000 \\
GO:0010035 & Response to inorganic substance & 0.000000 \\
GO:0008283 & Cell proliferation & 0.000000 \\
GO:0006260 & DNA replication & 0.000000 \\
GO:0005975 & Carbohydrate metabolic process & 0.000004 \\
GO:0006629 & Lipid metabolic process & 0.000088 \\
GO:0009725 & Response to hormone & 0.000276 \\
GO:0044550 & Secondary metabolite biosynthetic process & 0.000291 \\
GO:0000281 & Mitotic cytokinesis & 0.000378 \\
GO:0061640 & Cytoskeleton-dependent cytokinesis & 0.000378 \\
GO:0051301 & Cell division & 0.001546 \\
GO:0019344 & Cysteine biosynthetic process & 0.001784 \\
\hline
\end{tabular}

\section{The significant $D_{\mathrm{HP}}$ related to grain yield $\mathrm{QTLs}$}

We compared the significantly enriched $\mathrm{DG}_{\mathrm{HP}}$ to grain yield QTLs. As shown in Table 6, among the $\mathrm{DG}_{\mathrm{HP}}$-correlated QTLs, many QTLs were well characterized, including those for grain per panicle (e.g., qGP-1a (Yu et al. 1997), $q N G-1$ (Lin et al. 1996), $q G P 3-1$ (Li et al. 2001), $q G P P-4$ (Xiao et al. 1996), qGP-6 (Hua et al. 2002), qGP-7a (Li et al. 2000)); number of spikelets on secondary branches per panicle (e.g., qSSBP1-1 (Cui et al., 2002)); spikelet number per panicle (e.g., $q S N P-3 b$ (Xu et al. 2001), $q S N P-4 a$ (Mei et al. 2006), qSNP4-1 (Takai et al. 2005), qSP6-1 (Zhuang et al. 2001), qSNP-6 (He et al. 2001), $q N F P B-11$ (Yamagishi et al. 2004)); spikelet density (e.g., $q S D-15$ (Li et al. 1998) and qSSD-10 (Xiao et al. 1996)); 1000-grain weight (e.g., qgw362 (Ishimaru 2003), qGW3.1 (Thomson et al. 2003),

Table 5 Significant GO Terms of DG B Between BS and YS in the Biological Process Category

\begin{tabular}{lll}
\hline GO ID & Description & $p$-value \\
\hline GO:0006950 & Response to stress & 0.000012 \\
GO:0050896 & Response to stimulus & 0.000047 \\
GO:0048645 & Organ formation & 0.006863 \\
GO:0071265 & L-methionine biosynthetic process & 0.008974 \\
GO:0009686 & Gibberellin biosynthetic process & 0.009689 \\
GO:0010160 & Formation of organ boundary & 0.011830 \\
GO:0003156 & Regulation of organ formation & 0.016135 \\
GO:0045596 & Negative regulation of cell differentiation & 0.016135 \\
GO:0048497 & Maintenance of floral organ identity & 0.016135 \\
GO:0010077 & Maintenance of inflorescence meristem identity & 0.017878 \\
GO:2000027 & Regulation of organ morphogenesis & 0.030664 \\
GO:0048586 & Regulation of long-day photoperiodism, & 0.034206 \\
& flowering & \\
GO:2000028 & Regulation of photoperiodism, flowering & 0.044460 \\
\hline
\end{tabular}

$q G w t 4 a$ (Lin et al. 1995), $q K w 5$ (Li et al. 1997), $q G w-6$ (Lu et al. 1996), and $q G w 7$ (Li et al. 2000)); and yield per plant (e.g., $y d 7 a$ (Li et al. 2000)).

The potential association between $\mathrm{DG}_{\mathrm{HP}}$ and QTLs was also suggested within many QTL regions, including putative protein phosphatase 2C (Os01g0846300) with qSSBP1-1 for the number of spikelets on secondary branches per panicle and putative transketolase (Os05g0408900) with $q S D-15$ for spikelet density. Interestingly, OsGA20ox1 (Os03g0856700), which is related to gibberellin biosynthesis, is located in both $q G P 3-1$ for the number of grains per panicle and $q S N P-3 b$ for the spikelet number per panicle. Putative fatty acid hydroxylase (Os04g0578400), which is involved in carotenoid biosynthesis, and OsSAUR20-Auxin-responsive SAUR gene family member (Os04g0608300) was shared in both qSNP4-1 for spikelet number per panicle and qGPP-4 for number of grains per panicle. Except for a small number of cloned genes, such as Os01g0788400, Os02g0697400, Os02g0771600, OsGA20ox1 (Os03g0 856700), Os03g0760200, Os03g0645900, Os04g0474800, Os04g0522500, Os04g0556500, Os05g0380900, Os07g01 54100, and Os07g0155600, the remaining genes(including Os01g0846300, Os05g0408900, Os04g0578400 and Os04g0608300), which have been located in grain yield QTLs (including grain number, 1000-grain weight, and yield), were not cloned. Studying the function of these candidate transcripts in these QTL regions may increase the knowledge of the molecular mechanisms underlying heterosis.

\section{Transcription factors probably underlying heterosis}

Since transcripts are always under different levels of regulation, such as transcription and splicing through genetic or epigenetic mechanisms, the detailed sequence comparisons and validations for different alleles of annotated $\mathrm{DG}_{\mathrm{HP}}$ are not suitable to display in this current report. Transcription factors (TFs) are certainly one of the causes of gene expression fluctuations. In this study, we indeed found that 51 TFs showed significant differential expression in the hybrid compared with the maternal line (Additional file 6: Table S5). It is a coincidence that a previous study also proposed that altered gene expression caused by interactions between transcription factor allelic promoter regions in hybrids was one reasonable mechanism underlying heterosis in rice (Zhang et al. 2008).

Furthermore, among the 51 TFs, we found that $L A X 1$, which is the main regulator involved in the formation of axillary bud primordium in rice, is overrepresented in the hybrid (Komatsu et al. 2003). MADS-box 55 (MADS50) was up-regulated significantly, and MADS-box 56 (MADS56) was down-regulated in the hybrid compared to the maternal line (Additional file 6: Table S5). This is consistent with a previous study that suggests that OsMADS50 and 


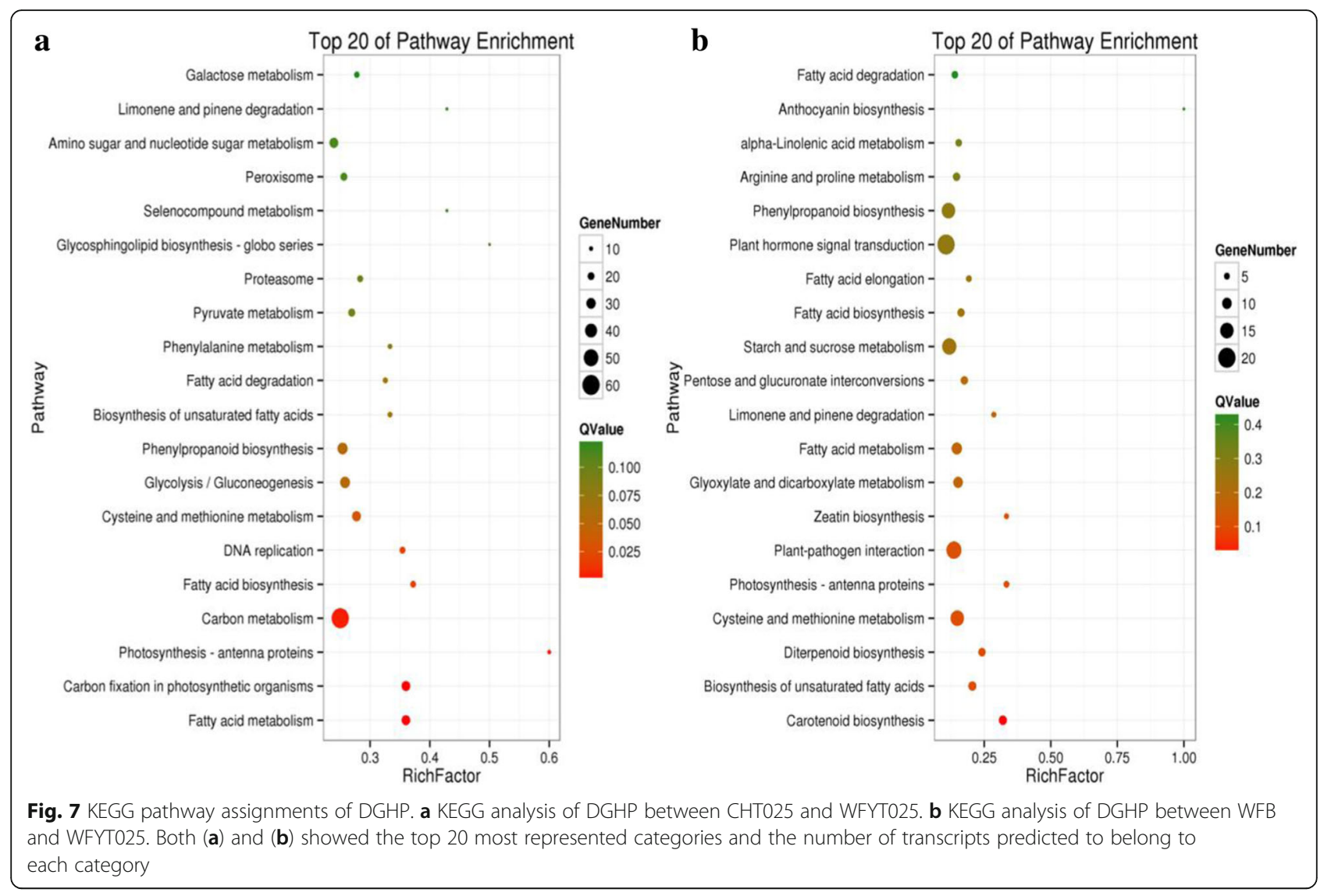

OsMADS56 function antagonistically in regulating LD-dependent flowering (Ryu et al. 2009). Certainly, except for 21 reported TFs, the remaining 30 novel TFs might play an important role in the young panicle and grain number heterosis.

\section{Conclusions}

In this study, we systematically investigated the transcriptome profiles from super-hybrid rice WFYT025 combinations for young panicles at the panicle differentiation stage by deep high-quality sequencing. We obtained a large amount of $\mathrm{DG}_{\mathrm{HP}}$ and found that the over-dominance effect is the main mode of inheritance for $\mathrm{DG}_{\mathrm{HP}}$. Comparing the significantly enriched $\mathrm{DG}_{\mathrm{HP}}(P<0.05)$ between WFYT025 and WFB with QTLs in response to grain number, we found some candidate transcripts that may contribute to the increase in grain yield. Exploring these candidate transcripts will provide new opportunities for revealing the heterosis of grain yield.

\section{Methods}

Plant materials and growth conditions

The hybrid WFYT025 along with its parental lines Changhui T025 (CHT025) and Wufeng B (WFB) were planted in the experimental field of Jiangxi Agricultural University. WFYT025 is a super-hybrid rice combination derived from the cross between female parent WFB and male parent CHT025. WFYT025 and the two parents were sown at the experimental plot in Jiangxi Agricultural University in a completely randomized block design with three replications in autumn 2016. Each plot consisted of 50 rows, with each row consisting of 10 plants, each separated from its neighbour by $20 \mathrm{~cm}$. Crop management followed normal procedures for rice. These three lines were selected in this study to measure phenotypic traits and conduct transcriptome analyses. At maturity time, panicles were selected with ten replicates for the estimation of heterosis. The young panicles at the differentiation stage were collected and stored at $-80{ }^{\circ} \mathrm{C}$ for RNA-Seq analysis, and each sample had at least three biological replications to minimize systematic errors.

\section{Panicle heterosis measurements}

To determine 1000-grain weight, panicles were dried in an oven at $42{ }^{\circ} \mathrm{C}$ for 1 week. Panicle length, primary branch, secondary branch, number of filled grains and total grain number were measured manually. Mid-parent heterosis $(\mathrm{MPH})$ and higher parent heterosis $(\mathrm{HPH})$ 
Table 6 Significant differentially Expressed Transcripts Mapped in each of the QTL Regions

\begin{tabular}{|c|c|c|c|c|}
\hline Trait & QTL & Chr & Intervel & $D G_{H P}$ \\
\hline GPP & $q G P-1 a$ & 1 & RM1-R753 & Os01G0135700, Os01G0150800 \\
\hline NGP & qNG-1 & 1 & RG374-RG394 & Os01G0788400 \\
\hline NSP & qSSBP1-1 & 1 & $\mathrm{C} 86-\mathrm{C} 2340$ & Os01G0846300 \\
\hline GW & $9 g w 362$ & 2 & C1445-C560 & Os02G0697400, Os02G0771600 \\
\hline GPP & qGP3-1 & 3 & G249-RG418 & $\begin{array}{l}\text { Os03G0760200,Os03G0762400, } \\
\text { Os03G0797800, Os03G0856700 }\end{array}$ \\
\hline SNPP & $a S N P-3 b$ & 3 & RM227-RM85 & Os03G0856700 \\
\hline GW & qGW3.1 & 3 & RZ672-RZ474 & Os03G0423300, Os03G0645900 \\
\hline GW & qGwt4a & 4 & RG788-RG190 & Os04G0229100 \\
\hline SNPP & aSNP-4a & 4 & RM401-RM335 & $\begin{array}{l}\text { Os04G0229100,Os04G0474800, } \\
\text { Os04G0486950, }\end{array}$ \\
\hline GPP & qGPP-4 & 4 & RZ569-RZ565 & $\begin{array}{l}\text { Os04G0492800,Os04G0498700, } \\
\text { Os04G0518100, Os04G0522500 } \\
\text { Os04G0535600,Os04G0556500, } \\
\text { Os04G0565200, Os04G0578400, } \\
\text { Os04G0608300,Os04G0611700, } \\
\text { Os04G0611800,Os04G0618700 }\end{array}$ \\
\hline SNPP & qSNP4-1 & 4 & RM303-RM255 & Os04G0578400,Os04G0608300 \\
\hline GW & qKW5 & 5 & RG182-RG13 & Os05G0374200, Os05G0380900 \\
\hline SD & qSD-15 & 5 & RG13-RG346 & $\begin{array}{l}\text { Os05G0475400,Os05G0551700, } \\
\text { Os05G0408900 }\end{array}$ \\
\hline GW & $q G w-6$ & 6 & C235-G294 & Os06G0347100, Os06G0486900 \\
\hline SP & $q S P 6-1$ & 6 & RG138-RZ398 & Os06G0185100 \\
\hline GPP & $q G P-6$ & 6 & RZ667-RG424 & Os06G0347100 \\
\hline SSP & qSPN-6 & 6 & C236-G294 & Os06G0486900 \\
\hline GW & $q G w 7$ & 7 & R1440-RG128 & Os07G0154100, Os07G0155600 \\
\hline YPP & $y d 7 a$ & 7 & R1440-RG128 & Os07G0154100, Os07G0155600 \\
\hline GPP & $q G P-7 a$ & 7 & R1440-RG128 & Os07G0154100 \\
\hline SSD & aSSD-10 & 10 & RG257-RZ583 & $\begin{array}{l}\text { Os10G0419400,Os10G0422200, } \\
\text { Os10G0430200, Os10G0472900 }\end{array}$ \\
\hline NFPB & qNFPB-11 & 11 & RM286-RM332 & Os11G0141400, Os11G0152700 \\
\hline
\end{tabular}

were calculated for these traits according to the following formulas: $\mathrm{MPH}=\left(\mathrm{F}_{1}-\mathrm{MP}\right) / \mathrm{MP}$ and $\mathrm{HPH}=\left(\mathrm{F}_{1}-\right.$ $\mathrm{BP})$ / $\mathrm{BP}$, where $\mathrm{F}_{1}$ is the performance of the hybrid, MP is the average performance of the two parents and $\mathrm{BP}$ is the performance of better parents. Hypothesis testing was performed using a $t$-test.

RNA extraction, cDNA library preparation and sequencing Total RNA was extracted from rice panicles using Trizol reagent (Invitrogen, Carlsbad, CA, USA) and purified using an RNeasy Plant Mini Kit (Qiagen, Valencia, CA, USA) according to the manufacturer's instructions. The quality and integrity of RNA were tested using an Agilent Bioanalyzer 2100 system (Agilent, Santa Clara, CA, USA); RNA Integrity Number (RIN) values were greater than 8.5 for all samples. After total RNA extraction, eukaryotic mRNA was enriched by Oligo (dT) beads, while prokaryotic mRNA was enriched by removing rRNA using the Ribo-Zero TM
Magnetic Kit (Epicentre). Then, the enriched mRNA was fragmented into 200-bp segments using fragmentation buffer and reverse transcribed into cDNA with random primers. Second-strand cDNA synthesis was subsequently performed using DNA polymerase I, RNase $\mathrm{H}, \mathrm{dNTP}$ and buffer. Then, the cDNA fragments were purified with QIAquick PCR extraction kit, end repaired, poly (A) added, and ligated to Illumina sequencing adapters. The ligation product size was selected by agarose gel electrophoresis, PCR amplified, and sequenced with 100 cycles of paired-end sequencing $(2 \times 150 \mathrm{bp})$ using Illumina HiSeq TM 2500 by Gene Denovo Biotechnology Co. (Guangzhou, China). The processing of fluorescent images into sequences, base-calling and quality value calculations were performed using the Illumina data processing pipeline (version 1.8). The sequence reads were submitted to the NCBI Sequence Read Archive (SRA, http://www.ncbi.nlm.nih.gov/sra) under the accession number SRP127997. 
Identification of differentially expressed mRNAs

Raw reads generated from high-throughput sequencing were treated as follows. First, to remove adapters that were added for reverse transcription and sequencing, sequences with too many unknown bases $(>10 \%)$ and low-quality bases $(>50 \%$ of the bases with a quality score $\leq$ 20) were removed. The reads mapped to the ribosome RNA (rRNA) database were removed with the read alignment tool Bowtie 2 (Langmead and Salzberg 2012). The remaining reads of each sample were then mapped to the Nipponbare reference genome (IRGSP build 1.0) by TopHat2 (version 2.0.3.12) (Kim et al. 2013). The parameters for alignment were set as follows: 1 ) the maximum read mismatch should be $2 ; 2$ ) the distance between mate-pair reads should be $50 \mathrm{bp} ; 3$ ) the error of distance between mate-pair reads should be $\pm 80 \mathrm{bp}$. Differential expression was estimated and tested using the software package edge $R$ ( $R$ version: 2.14, edge $R$ version: 2.3.52) (Robinson et al. 2010). We quantified gene expression levels in terms of fragments per $\mathrm{kb}$ for a million reads (FPKM) (Mortazavi et al. 2008), calculated the false discovery rate (FDR), and estimated the fold change (FC) and $\log _{2}$ values of $\mathrm{FC}$. Transcripts that exhibited an $\mathrm{FDR} \leq$ 0.05 and an estimated absolute $\log _{2}(\mathrm{FC}) \geq 1$ were considered to be significantly differentially expressed.

\section{The mode of inheritance analysis}

For statistical analysis, the analysis of variance (ANOVA) was usually by the model: $\mathrm{y}=\mathrm{u}+(\mathrm{GA})+(\mathrm{GD})+(\mathrm{SR})+\mathrm{e}$, where $y$ is the acquired gene expression, $u$ is the overall mean, GA is the additive effect, GD is the dominant effect, $\mathrm{SR}$ is the replication effect, and e is the residual error (Lynch and Walsh 1998). $\mathrm{Hp}=[\mathrm{d}] /[\mathrm{a}]$, referred to as the dominance ratio or potency (where [a] and [d] represent GA and GD, respectively), was also calculated to measure the non-additivity of the $F_{1}$ hybrid relative to its parents (Griffing 1990). Considering gene expression levels as quantitative traits, we adopted traditional quantitative genetic parameters, such as composite additive effect [a] and composite dominance effect [d], to estimate our expression profile. $\mathrm{DG}_{\mathrm{HP}}$ were classified according to the dominance ratio $\mathrm{Hp}(=[\mathrm{d}] /[\mathrm{a}])$, based on $99.8 \%$ confidence intervals constructed for $[d]-[a]([d]>0)$ and $[d]$ $+[a]([d]<0)$. According to the value of $\mathrm{Hp}(=[\mathrm{d}] /[\mathrm{a}])$, we considered that these genes belonged to partial dominance $(-0.8<\mathrm{Hp} \leq-0.2$ or $0.2<\mathrm{Hp} \leq 0.8)$, over-dominance ( $\mathrm{Hp} \leq-1.2$ or $\mathrm{Hp}>1.2)$, dominance $(-1.2<\mathrm{Hp} \leq-0.8$ or $0.8<\mathrm{Hp} \leq 1.2)$ and additive effect $(-0.2<\mathrm{Hp} \leq 0.2)$ (Stuber et al. 1987, Bian et al. 2011).

\section{Cluster analysis}

Cluster analysis of all annotated transcripts from the hybrid and its parents was performed. The FPKM-normalized expression counts for each transcript were clustered with the software Cluster 3.0, and the results were visualized using Treeview (Eisen et al. 1998).

\section{Real-time quantitative PCR}

The expression of genes with differential expression (DEGs) and results of RNA sequencing were validated by quantitative real-time PCR. Total RNA from nine samples (including three biological replicates) was extracted using the Prime Script ${ }^{\mathrm{TM}} \mathrm{RT}$ reagent Kit with gDNA Eraser according to the manufacturer's instructions. SYBR-based qRT-PCR reactions (SYBR Green I, Osaka, Japan) were performed on an ABI VIIA@7 using the following thermal cycling conditions: $50{ }^{\circ} \mathrm{C}$ for 2 min; $95{ }^{\circ} \mathrm{C}$ for 5 min followed by 40 cycles at $95^{\circ} \mathrm{C}$ for $15 \mathrm{~s}$ and $60^{\circ} \mathrm{C}$ for $34 \mathrm{~s}$. All qRT-PCR reactions were performed in triplicate samples, and the results were analysed with the system's relative quantification software (ver. 1.5) based on the $(\Delta \Delta C T)$ method. The detection of the threshold cycle for each reaction was normalized against the expression level of the rice Actin 1 gene with the primer sequences $5^{\prime}$-TGGCATCTCTCAGCACATT CC-3' and 5' -TGCACAATGGATGGGTCAGA-3'.

\section{Additional files}

Additional file 1: Figure S1. Scatterplots comparing gene expression scores from biological replicates of WFYT025 and its parents. CS 1-3, YS 1 3, and BS 1-3 denote biological replicates from CHT025, WFYT025 and WFB, respectively. (DOC $142 \mathrm{~kb}$ )

Additional file 2: Table S1. Primer sequences for qRT-PCR expression analysis. (XLS $17 \mathrm{~kb}$ )

Additional file 3: Table S2. The FPKM of all transcripts. (XLS $113176 \mathrm{~kb}$ ) Additional file 4: Table S3. Classification of $\mathrm{DG}_{\mathrm{HP}}$ based on the dominance ratio $H_{P}$. (XLS $526 \mathrm{~kb}$ )

Additional file 5: Table S4. The mode of inheritance of cloned genes. (XLS $45 \mathrm{~kb}$ )

Additional file 6: Table S5. The DG $G_{H P}$ of all transcription factors between WFYT025 and WFB. (XLS 63 kb)

\section{Abbreviations}

ABA: Abscisic Acid; DEGs: The Genes with Different Expression; DGHp: The Genes with Different Expression Between the Hybrid and Parents; DGpp: The Genes with Different Expression Between Paternal Line and Maternal Line; FC: Fold Change; FDR: False Discovery Rate; FPKMs: Fragments Per kb for a Million Reads; GA: Gibberellins; GO: Gene Ontology; GPP: Grain per Panicle; GPP: Grains per Panicle; GW: Grain Weight; HPH: Higher Parent Heterosis; KEGG: Kyoto Encyclopedia of Genes and Genomes; MPH: Mid-Parent Heterosis; NFPB: Number of Florets per Branch; NGP: Number of Grains per Panicle; NSP: Number of Spikelets on Secondary Branches Per Panicle; PP2C: Type-2C Protein Phosphatase; qRT-PCR: Quantitative Real-Time Polymerase Chain Reaction; QTL: Quantitative Trait Locus; RNA-seq: RNA Sequencing Technology; SD: Spikelet Density; SNPP: Spikelet Number per Panicle; SnRK2: SNF1-Related Protein Kinase2; SP: Spikelet Number per Panicle; SSD: Spikelets Setting Density; SSP: Spikelet Number per Panicle; TFs: Transcription Factors; WEGO: Web Gene Ontology Annotation Plot Software; YPP: Yield per Plant

\section{Acknowledgements}

We thank the anonymous referees for their critical comments on this manuscript. 


\section{Funding}

This research was supported by grant (2016YFD0101801) from The National Key Research and Development Program of China and Technology Department, grant (31560386) from National Nature Science Foundation of China and grant (201710410018) from National Undergraduate Training Program for Innovation and Entrepreneurship.

\section{Availability of data and materials}

The clean data with high quality in this study have been deposited into the NCBI Sequence Read Archive under the accession number of SRP127997.

\section{Authors' contributions}

$\mathrm{HH}$ and JB conceived and designed the experiments. LC conceived and designed the experiments, and wrote the manuscript. SS and JY performed the experiments. CZ, LX, ST, XY, XP, QY, XH, JF, XC, LH, LO analyzed the data. $H K$ and GMW revised the manuscript for the language. All authors read and approved the final manuscript.

\section{Consent for publication}

\section{Not applicable.}

\section{Competing interests}

The authors declare that they have no competing interests.

\section{Publisher's Note}

Springer Nature remains neutral with regard to jurisdictional claims in published maps and institutional affiliations.

\section{Author details}

${ }^{1}$ Key Laboratory of Crop Physiology, Ecology and Genetic Breeding, Ministry of Education, Jiangxi Agricultural University, Nanchang 330045, China. ${ }^{2}$ College of Agronomy, Jiangxi Agricultural University, Nanchang 330045, China. ${ }^{3}$ Southern Regional Collaborative Innovation Center for Grain and Oi Crops in China, Changsha, China.

Received: 17 January 2018 Accepted: 6 June 2018

Published online: 15 June 2018

\section{References}

Bian JM, Jiang L, Liu LL, Xiao YH, Wang ZQ, Zhao ZG, Zhai HQ, Wan JM (2011) Identification of japonica chromosome segments associated with Heterosis for yield in Indica × japonica Rice hybrids. Crop Sci 50:2328-2337

Birchler JA, Auger DL, Riddle NC (2003) In search of the molecular basis of heterosis. Plant Cell 15:2236-2239

Cowling RJ, Kamiya Y, Seto H, Harberd NP (1998) Gibberellin dose-response regulation of GA4 gene transcript levels in Arabidopsis. Plant Physiol 117:1195

Cui KH, Peng SB, Xing YZ, Yu SB, Xu CG (2002) Genetic analysis of the panicle traits related to yield sink size of rice. Acta Genet Sin 29:144-152

Davenport CB (1908) Degeneration, albinism and inbreeding. Science 28:454

Eisen MB, Spellman PT, Brown PO, Botstein D (1998) Cluster analysis and display of genome-wide expression patterns. Proc Natl Acad Sci 95:14863-14868

Evans MM, Poethig RS (1995) Gibberellins promote vegetative phase change and reproductive maturity in maize. Plant Physiol 108:475

Griffing B (1990) Use of a controlled-nutrient experiment to test heterosis hypotheses. Genetics 126:753-767

He G, Luo XJ, Tian F, Li K, Zhu ZF, Su W, Qian XY, Fu YC, Wang XK, Sun CQ, Yang JS (2006) Haplotype variation in structure and expression of a gene cluster associated with a quantitative trait locus for improved yield in rice. Genome Res 16:618-626

He G, Zhu X, Elling AA, Chen L, Wang X, Guo L, Liang M, He H, Zhang H, Chen F, Qi Y, Chen R, Deng XW (2010) Global epigenetic and transcriptional trends among two rice subspecies and their reciprocal hybrids. Plant Cell 22:17-33

He P, Li JZ, Zheng XW, Shen LS, Lu CF, Chen Y, Zhu LH (2001) Comparison of molecular linkage maps and agronomic trait loci between DH and RIL populations derived from the same Rice cross. Crop Sci 41:1240-1246

Hua JP, Xing YZ, Xu CG, Sun XL, Yu SB, Zhang Q (2002) Genetic dissection of an elite rice hybrid revealed that heterozygotes are not always advantageous for performance. Genetics 162:1885

Huang X, Yang S, Gong J, Zhao Y, Feng Q, Gong H, Li W, Zhan Q, Cheng B, Xia J, Chen N, Hao Z, Liu K, Zhu C, Huang T, Zhao Q, Zhang L, Fan D, Zhou C, Lu Y, Weng Q, Wang ZX, Li J, Han B (2015) Genomic analysis of hybrid rice varieties reveals numerous superior alleles that contribute to heterosis. Nat Commun 6:6258
Huang Y, Zhang L, Zhang J, Yuan D, Xu C, Li X, Zhou D, Wang S, Zhang Q (2006) Heterosis and polymorphisms of gene expression in an elite rice hybrid as revealed by a microarray analysis of 9198 unique ESTs. Plant Mol Biol 62:579-591

Ishimaru K (2003) Identification of a locus increasing Rice yield and physiological analysis of its function. Plant Physiol 133:1083-1090

Kim D, Pertea G, Trapnell C, Pimentel H, Kelley R, Salzberg SL (2013) TopHat2: accurate alignment of transcriptomes in the presence of insertions, deletions and gene fusions. Genome Biol 14:R36

Komatsu K, Maekawa M, Ujiie S, Satake Y, Furutani I, Okamoto H, Shimamoto K, Kyozuka J (2003) LAX and SPA: major regulators of shoot branching in rice. Proc Natl Acad Sci 100:11765-11770

Kusterer BJ, Muminovic HF, Utz HP, Piepho S, Barth M, Heckenberger RC, Meyer T, Melchinger AE (2007) Analysis of a triple testcross design with recombinant inbred lines reveals a signifcant role of epistasis in heterosis for biomassrelated traits in Arabidopsis. Genetics 175:2009-2017

Langmead B, Salzberg SL (2012) Fast gapped-read alignment with bowtie 2. Nat Methods 9:357-359

Li JX, Yu SB, Xu CG, Tan YF, Gao YJ, Li XH, Zhang QF (2000) Analyzing quantitative trait loci for yield using a vegetatively replicated F2 population from a cross between the parents of an elite rice hybrid. Theor Appl Genet 101:248-254

Li Z, Pinson SR, Park WD, Paterson AH, Stansel JW (1997) Epistasis for three grain yield components in rice (Oryza sativa L.). Genetics 145:453-465

Li Z, Pinson SRM, Stansel JW, Paterson AH (1998) Genetic dissection of the source-sink relationship affecting fecundity and yield in rice (Oryza sativa L.). Mol Breed 4:419-426

Li ZK, Luo LJ, Mei HW, Wang DL, Shu QY, Tabien R, Zhong DB, Ying CS, Stansel JW, Khush GS, Paterson AH (2001) Overdominant epistatic effect loci are the primary genetic basis of inbreeding depression and heterosis in rice. II. Grain yield components. Genetics 158:1737-1753

Lin HX, Qian HR, Zhuang JY, Lu J, Min SK, Xiong MZ, Huang N, Zheng KL (1995) Interval mapping of QTLs for yield and other related characters in rice. Rice Genet Newslett 12:251-253

Lin HX, Qian HR, Zhuang JY, Lu J, Min SK, Xiong ZM, Huang N, Zheng KL (1996) RFLP mapping of QTLs for yield and related characters in rice (Oryza sativa L. ). Theor Appl Genetics 92:920-927

Lu C, Shen L, Tan Z, Xu Y, He P, Chen Y, Zhu L (1996) Comparative mapping of QTLS for agronomic traits of rice across environments using a doubled haploid population. TAG Theor Appl Genet 93:1211-1217

Lynch M, Walsh B (1998) Genetics Analysis of Quantitative Traits. Sinauer Associates Press, Sunderland

Mei HW, Xu JL, Li ZK, Yu XQ, Guo LB, Wang YP, Ying CS, Luo LJ (2006) QTLS influencing panicle size detected in two reciprocal introgressive line (IL) populations in rice (Oryza sativa L.). Theor Appl Genet 112:648-656

Merlot S, Gosti F, Guerrier D, Vavasseur A, Giraudat J (2001) The ABI1 and ABI2 protein phosphatases $2 \mathrm{C}$ act in a negative feedback regulatory loop of the abscisic acid signalling pathway. Plant I 25:295

Mortazavi A, Williams BA, McCue K, Schaeffer L, Wold B (2008) Mapping and quantifying mammalian transcriptomes by RNA-Seq. Nat Methods 5:621-628

Poethig RS (1990) Phase change and the regulation of shoot morphogenesis in plants. Science 250:923

Robinson MD, McCarthy DJ, Smyth GK (2010) edgeR: a Bioconductor package for differential expression analysis of digital gene expression data. Bioinformatics 26:139-140

Ryu CH, Lee S, Cho LH, Kim SL, Lee SY, Choi SC, Jeong HJ, Yi J, Park SJ, Han CD, An G (2009) OsMADS50 and OsMADS56 function antagonistically in regulating long day (LD)-dependent flowering in rice. Plant Cell Environ 32: 1412-1427

Shull GH (1908) The composition of a field of maize. Am Breed Assoc Rep 4:296-301

Song GS, Zhai HL, Peng YG, Zhang L, Wei G, Chen XY, Xiao YG, Wang L, Chen YJ, Wu B, Chen B, Zhang Y, Chen H, Feng XJ, Gong WK, Liu Y, Yin ZJ, Wang F, Liu GZ, Xu HL, Wei XL, Zhao XL, Ouwerkerk PB, Hankemeier T, Reijmers T, Heijden RVD, Lu C, Wang M, Greef JVD, Zhu Z (2010) Comparative transcriptional profiling and preliminary study on heterosis mechanism of super-hybrid rice. Mol Plant 3:1012-1025

Stuber C, Edwards M, Wendel J (1987) Molecular marker-facilitated investigations of quantitative trait loci in maize. II. Factors influencing yield and its component traits. Crop Sci 27(4):639-648

Takai T, Fukuta Y, Shiraiwa T, Horie T (2005) Time-related mapping of quantitative trait loci controlling grain-filling in rice (Oryza sativa L.). J Exp Bot 56:2107-2118 
Thomson M, Tai T, McClung A, Lai X, Hinga M, Lobos K, Xu Y, Martinez C, McCouch S (2003) Mapping quantitative trait loci for yield, yield components and morphological traits in an advanced backcross population between Oryza rufipogon and the Oryza sativa cultivar Jefferson. Theor Appl Genet 107:479-493

Wei G, Tao Y, Liu G, Liu G, Chen C, Luo R, Xia H, Gan Q, Zeng H, Lu Z, Han Y, Li X, Song G, Zhai H, Peng Y, Li D, Xu H, Wei X, Cao M, Deng H, Xin Y, Fu X, Yuan L, Yu J, Zhu Z, Zhu L (2009) A transcriptomic analysis of superhybrid rice LYP9 and its parents. Proc Natl Acad Sci 106:7695-7701

Wu Y, Wang Y, Mi XF, Shan JX, Li XM, Xu JL, Lin HX (2016) The QTL GNP1 encodes GA200x1, which increases grain number and yield by increasing Cytokinin activity in Rice panicle meristems. PLoS Genet 12:e1006386

Xiao J, Li J, Yuan L, Tanksley SD (1996) Identification of QTLs affecting traits of agronomic importance in a recombinant inbred population derived from a subspecific rice cross. Theo Appl Genet 92:230

Xu JL, Xue QZ, Luo L, Li ZK (2001) OTL Dissection of Panicle Number Per Plant and Spikelet Number Per Panicle in Rice (Oryza sativa L.). Acta Genet Sin 28:752-759

Xu ML, Jin ZX, Li XG, Zhang ZC, Liu HY, Zhang FZ, Zhao SY, Zhang HB (2009) Comparison of genetic distance among seven cultivars of japonica Rice based on SSR and SRAP and its relationship with Heterosis of yield traits. Molecular Plant Breeding: 2009-06

Yamagishi J, Miyamoto N, Hirotsu S, Laza RC, Nemoto K (2004) QTLs for branching, floret formation, and pre-flowering floret abortion of rice panicle in a temperate japonica $\times$ tropical japonica cross. Theor Appl Genet 109:1555

Ye J, Fang L, Zheng H, Zhang Y, Chen J, Zhang Z, Wang J, Li S, Li R, Bolund L, Wang J (2006) WEGO: a web tool for plotting GO annotations. Nucleic Acids Res 34:293-297

Yu SB, Li JX, Xu CG, Tan YF, Gao YJ, Li XH, Zhang QF, Maroot MAS (1997) Importance of epistasis as the genetic basis of heterosis in an elite rice hybrid. Proc Natl Acad Sci 94:9226-9231

Zhai R, Feng Y, Wang H, Zhan X, Shen X, Wu W, Zhang Y, Chen D, Dai G, Yang Z, Cao L, Cheng S (2013) Transcriptome analysis of rice root heterosis by RNASeq. BMC Genomics 14:19

Zhang HY, He H, Chen LB, Li L, Liang MZ, Wang XF, Liu XG, He GM, Chen RS, Ma LG, Deng XW (2008) A genome-wide transcription analysis reveals a close correlation of promoter INDEL polymorphism and heterotic gene expression in rice hybrids. Mol Plant 1:720-731

Zhuang JY, Fan YY, Wu JL, Xia YW, Zheng KL (2001) Comparison of the detection of QTL for yield traits in different generations of a rice cross using two mapping approaches. Acta Genet Sin 28:458

\section{Submit your manuscript to a SpringerOpen ${ }^{\circ}$ journal and benefit from:}

- Convenient online submission

- Rigorous peer review

- Open access: articles freely available online

- High visibility within the field

- Retaining the copyright to your article

Submit your next manuscript at $\gg$ springeropen.com 